\title{
Elementos de história da terminografia médica no Brasil
}

\author{
Lídia Almeida Barros \\ UNESP-Universidade Estadual Paulistal ${ }^{\text {(Brasil) }}$
}

\section{INTRODUÇÃO}

Ao procedermos a uma pesquisa sobre a história da Terminografia médica no Brasil, defrontamo-nos com algumas questões fundamentais à delimitação do campo de estudo e à abordagem a ser adotada. Verificamos que uma pesquisa de cunho histórico sobre os dicionários especializados (em Medicina ou em qualquer outro domínio técnico ou científico) que deseje ser abrangente não pode se ater ao conceito atual de Terminografia.

Ao estudarmos as obras brasileiras que vão do período colonial até ao final do século XIX, apresentaram-se alguns elementos que consideramos preciosos para o estudo da história dos dicionários brasileiros especializados que não seriam levados em consideração caso nos ativéssemos à Terminografia stricto sensu.

Nesse sentido, alargamos nosso campo de pesquisa a elementos de história da Lexicografia especializada; incorporamos também ao nosso corpus documentos que, dentro de uma tipologia geral de obras, não se caracterizam de modo algum como dicionários, mas que:

1. são documentos técnicos ou científicos;

2. abordam temas de domínios especializados;

1 Trabalho apresentado no evento Curso "Terminologia no Outono", tendo recebido apoio financeiro da Fundação para o Desenvolvimento da UNESP-FUNDUNESP. 
3. têm como objetivos registrar conhecimentos especializados e transmiti-los;

4. para tanto, empregam conjuntos terminológicos que representam e transmitem esses conhecimentos;

5. em seu interior, dão a alguns dados um tratamento que se assemelha ao lexicográfico, ou seja, nos quais:

a. termos são descritos, no próprio corpo do texto, por meio de um enunciado parafrástico de tipo definicional;

b. termos são descritos em enunciados que são dispostos, no plano formal e gráfico, isoladamente uns dos outros (em forma de verbetes),

c. esses termos constituem "entradas" desses "verbetes";

d. as mensagens se organizam em dois sentidos, a saber: verticalmente (na "macroestrutura") e horizontalmente (na "microestrutura");

e. os enunciados "lexicográficos" transmitem informações de tipo lingüístico, metalingüístico ou enciclopédico.

Nesse sentido, muitos textos científicos elaborados no período colonial brasileiro apresentam as características que acabamos de mencionar. Embora não sejam dicionários, neles encontramos um saber terminológico, no sentido de conhecimento provindo da descrição do léxico especializado empregado nesses documentos. Também ali se observa um tratamento de tipo "dicionarístico" dos dados terminológicos, estes últimos entendidos como "dados relativos a um conceito ou à sua designação” (ISO 1087, 1990: 9).

Assim, consideramos que o resgate da história da Terminografia brasileira -e em nosso caso específico, da Terminografia médica no Brasil-, não pode alijar do estudo esse tipo de documento.

Cumpre ainda ressaltar que boa parte do trabalho de resgate da história da Lexicografia brasileira, executado por diversos cientistas da linguagem de nosso país, deu-se por meio da análise de textos de cunho técnico e científico. Nesse sentido, uma parte da história da Terminologia/Terminografia brasileira já teria sido estudada pela Lexicografia. 
Nosso objetivo neste trabalho é abordar alguns elementos de história da Terminografia/Lexicografia médica no Brasil. Para tanto, procuraremos, em um primeiro momento, evidenciar a presença de um discurso lexicográfico em obras científicas ou documentos produzidos nos primórdios da colonização portuguesa no Brasil. Recuperaremos também dados sobre os dicionários médicos produzidos ou publicados nesse país no período colonial e no século XIX. Antes, porém, de darmos início a essa análise, convém precisar alguns princípios teóricos nos quais nos baseamos e definir, de modo mais claro, nossa postura científica.

\section{PRESSUPOSTOS TEÓRICOS DE PARTIDA}

A história da Lexicografia brasileira encontra na tese de Doutorado de J. H. Nunes (1996) uma das melhores pesquisas. Para esse autor, estudá-la "implica considerar a história do saber sobre o léxico, desde a época colonial até o momento de reivindicação de uma língua nacional distinta do português de Portugal" (Nunes 1996: 1). Nesse sentido, propõe, com fins metodológicos, uma delimitação conceitual, a saber:

Para começar, faremos uma distinção entre o discurso de constituição do léxico e o discurso lexicográfico. O primeiro inclui diversas práticas que realizam um trabalho metalingüístico envolvendo elementos lexicais (segmentação, comentários, descrições, definições), com objetivos variados, por exemplo: descrever a natureza, produzir literatura, construir conceitos científicos. $\mathrm{O}$ segundo se refere a um domínio específico: o da elaboração de dicionários de língua. Trataremos esta prática como um trabalho de instrumentação da língua, que se realiza em vista de determinados interesses práticos. É sobretudo este último caso que nos interessa; mas importa também mostrar de que modo o primeiro domínio incide sobre o segundo ${ }^{2}$ (Nunes 1996: 4).

Numa linha de continuidade, que se inicia no discurso de constituição do léxico e chega ao discurso lexicográfico no Brasil, estabelece-se o que o autor chamou de saber lexicográfico:

2 Todos os destaques em negrito presentes nas citaões deste trabalho são nossos. 
O saber lexicográfico de que trataremos aqui é aquele que se inicia no Brasil com os primeiros escritos sobre o país. Nesse sentido, ele surge juntamente com a etnografia (conhecimento dos povos indígenas), a economia (mercantilismo) e a geopolítica (expansão territorial das nações européias), em seus momentos precursores, introduzido através de relatos de viajantes, colonos e missionários. Tais textos estão pontuados por citações de termos indígenas, de modo que é formulada uma constelação de comentários lexicais (Nunes 1996: 11).

Assim, o saber lexicográfico que marcou o período colonial brasileiro construiu-se (ou se manifestou em), em parte, de documentos que procediam a descrições das coisas da terra e do léxico que as designava, sem, entretanto, terem um caráter puramente lexicográfico. Assim, descreviam as palavras no próprio texto, utilizando, para tanto, um enunciado de tipo definicional; por vezes anexavam listas temáticas, que geralmente compreendiam termos em línguas indígenas com os respectivos equivalentes em português; ou, ainda, organizavam as informações sobre determinado termo em forma muito parecida com a de verbetes dos dicionários. Telmo Verdelho também observa a presença de uma lexicografia implícita em documentos portugueses antigos que não se caracterizavam como dicionários:

A emergência da escrita entre os vernáculos europeus, desde a recuada Idade Média, paralelamente à escolarização do latim, deu naturalmente origem à dicionarização das línguas vulgares. Gerou-se em primeiro lugar uma espécie de lexicografia implícita que tecia os próprios textos e facilitava a compreensão do vocabulário característico da escrita, forçosamente mais amplo e menos quotidiano do que o da língua oral. Os textos que dão testemunho das primeiras tentativas do uso da escrita em vernáculo português e ainda quase toda a produção textual subseqüente, até aos tempos modernos, vêm marcados por esse esforço metalingüístico de clarificação e autodescodificação, próximo da informação lexicográfica. Muitos textos medievais portugueses parecem ser construídos com a preocupação de fornecerem um fácil acesso à significação do seu próprio léxico, apresentando um estilo parafrástico, enquadrado por muitas palavras redundantes e freqüentemente entretecido por verdadeiras definições lexicográficas. Os exemplos mais elucidativos poderão recolher-se nos textos jurídicos de Afonso X, tais como as Partidas e o Foro Real traduzidos do castelhano logo nos primeiros séculos da escrita em língua portugue- 
sa. (Ferreira 1980 e 1987). Os textos da Casa de Avis, e muito especialmente o Leal Conselheiro de D. Duarte, oferecem também bons exemplos de fundo pré-dicionarístico que acompanhou o início da memória textual portuguesa. $\mathrm{O}$ Leal Conselheiro apresenta-se mesmo como obra de tipo paralexicográfico nas declarações do próprio autor ("E fillayo por hûu A B C de lealdade") (Verdelho 2002: 16).

Verifica-se, portanto, que, em Portugal e no Brasil, um saber lexicográfico ou uma lexicografia implícita marca diversos documentos antigos, embora por motivos e em situações diferentes, como não poderia deixar de ser, uma vez que "o saber lingüístico é um produto histórico, localizado em um tempo e em um espaço” (Nunes 2002).

No âmbito deste trabalho, apoiamo-nos nos conceitos propostos por Nunes (1996) e Verdelho (2002). Ao falarmos de "tratamento dicionarístico" aplicado a dados terminológicos, automaticamente somos induzidos a pensar em saber terminográfico. Convém, porém, a nosso ver, não empregar de modo generalizado essa expressão, uma vez que, se por um lado é verdade que em alguns documentos se evidencia um tratamento que em certos aspectos lembra a metodologia empregada pela Terminografia moderna, por outro, alguns documentos não permitem essa observação. Com efeito, por Terminografia a Norma ISO 1087 compreende "o registro, tratamento e apresentação de dados terminológicos obtidos por uma pesquisa terminológica” (ISO 1087: 1990). A Terminografia constitui, juntamente com a análise terminológica (entendida como o "estudo sistemático dos conceitos e dos termos de acordo com os princípios e métodos da ciência da Terminologia" (ibidem)), o trabalho terminológico, definido como uma "atividade relativa à sistematização e à representação dos conceitos, assim como da apresentação de terminologias de acordo com os princípios e métodos estabelecidos" (ibidem).

Nesse sentido, acreditamos ser mais prudente falar de modo genérico de saber lexicográfico ou ainda de discurso lexicográfico, reservando o emprego de saber terminográfico ou discurso terminográfico às manifestações discursivas que resultem de um tratamento dos dados que se assemelhe, de alguma maneira, ao adotado pela Terminografia atual. Quando nos referimos a textos que não recorrem a enunciados 
definicionais, mas que fornecem dados lingüísticos sobre termos, falaremos de discurso de constituição do léxico especializado ou de áreas de especialidade. Empregaremos a expressão saber terminológico em sentido genérico que engloba o discurso lexicográfico e o de constituição do léxico especializado.

\section{O SABER TERMINOLÓGICO EM DOCUMENTOS FUNDADORES DA IDENTIDADE NACIONAL}

O Brasil do início da colonização portuguesa foi intensamente descrito por viajantes ou cientistas de diferentes nacionalidades, em documentos que tinham fins vários. Dentre eles, podemos citar como de maior relevância:

\begin{tabular}{|l|l|l|}
\hline 1500 & Pero Vaz de Caminha & A Carta de Pero Vaz de Caminha \\
\hline 1555 & Hans Staden & Duas viagens ao Brasil \\
\hline 1560 & José de Anchieta & $\begin{array}{l}\text { Carta Latina - Quamplurimarum } \\
\text { rerum naturalium, quae S. Vicentii } \\
\text { (nunc S. Pauli) provinciam } \\
\text { incolunt, sistens descriptionem }\end{array}$ \\
\hline 1576 & Pero de Magalhães Gandavo & $\begin{array}{l}\text { História da Província Santa Cruz } \\
\text { a que vulgarmente chamamos } \\
\text { Brasil }\end{array}$ \\
\hline 1578 & Jean de Léry & $\begin{array}{l}\text { Histoire d'um Voyage faict em la } \\
\text { terre du Brésil autrement dit } \\
\text { Amerique }\end{array}$ \\
\hline 1583 & Fernão Cardim & Tratado da terra e gente do Brasil \\
\hline 1587 & Gabriel Soares de Souza & Tratado descritivo do Brasil \\
\hline 1618 & Ambrósio Fernandes Brandão & Diálogos da grandeza do Brasil \\
\hline 1648 & Georg Marcgrave e Willem Piso & História Natural do Brasil \\
\hline 1663 & Simão de Vasconcelos & $\begin{array}{l}\text { Crônica da Companhia de Jesus } \\
\text { do Estado do Brasil }\end{array}$ \\
\hline
\end{tabular}

Esses documentos, que podemos chamar de fundadores, contribuíram para a construção da identidade do Brasil no imaginário das sociedades da época e funcionam, ainda hoje, como pinturas faladas que re- 
tratam o país no período da chegada dos primeiros europeus. Em boa parte desses documentos, termos que designam plantas, doenças, animais e outros elementos são mencionados e descritos no corpo do texto; alguns apresentavam listas temáticas de palavras com o objetivo de explicar coisas exóticas ou relacionar designações indígenas a seus equivalentes em português ou outras línguas. Ao descreverem elementos desconhecidos dos colonizadores da época, produzia-se um discurso sobre o referente, como explica Nunes:

Os comentários dos viajantes se direcionam para as coisas do Novo Mundo, de maneira que a questão da referência torna-se importante nesse contexto. Ao descreverem as novidades do país, esses falantes colocam em evidência os referentes. Fala-se de lugares, animais, plantas nunca vistos (embora já nomeados pelos autóctones); fala-se de coisas não-idênticas, mas semelhantes; constata-se a existência ou inexistência de coisas. Nessas circunstâncias, a organização dos espaços lexicais está intimamente relacionada com a geografia e a economia, com os interesses de conquista e de comércio. Esse estado do saber lexicográfico envolve uma variada tipologia discursiva, em que se incluem narrações, descrições, traduções e diálogos. Temos em vista, sobretudo, os deslocamentos que ocorrem quando se passa de uma configuração dispersa, pontual, dos comentários lexicais inseridos nesses diferentes tipos de discurso, a uma configuração localizada, que já se pode observar nos próprios viajantes, com a elaboração de listas de palavras com comentários ou explicações (Nunes 1996: 12)

Nesse sentido, o saber lexicográfico que marcou o período colonial brasileiro constituiu-se, em parte, de documentos que procediam a descrições das coisas da terra, recorrendo, por vezes, para tanto, a um discurso de tipo lexicográfico. Essa é, aliás, uma das marcas discursivas dos documentos elaborados então, o que contribuiu para a construção de um saber sobre as coisas, suas denominações e conceitos. Na obra de Pero de Magalhães Gandavo, por exemplo, o Capítulo V é dedicado à flora brasileira e a outros aspectos relacionados à alimentação. Nele inúmeras plantas medicinais são descritas, como é o caso da copaíba, cujas propriedades podemos ler no texto desse autor: 


\section{HISTORIA DA PAONINCIA}

mantimentos que na cerra fe comem: ha ourtas de que os moradores fazem lisas fazendas, conuem 2 faber, muiras canas daçucre \& al godoaes, que he a principalf zenda que ha neftas parees, de que rodos fe ajudam \&c fazé muito proueito em cada hüa deftas capitanias, efpecial onére na de Paranambuco, que fam feicos perro de crinca engenhos, \& na da Bahia do Saluador qualioutros tanros, donde fe tira cada hum an no grande quan. tidade daçueares, \& fe dá infinito algodam, \& mais fem cóparaçam ḡ em nenhüa das outras. Tamberm ha mui co pao brafil neftas capicanias de que os mesmos mora. dores alcançam grande proveiro:o qual pao fe moftra claro, fer produzido da quentura do Sol, \& criado cons infuencia de feus rayos, porque nam le acha fe nam debajxo da Torridazona : \& alsi quäro mais pertocftá dalinha Equinocial, záro he mais fino \& de melhor tin ea. Eefta hea caufa porque on arm ha na capicania de $S$. Vicente, nem dahipera o Sul.

Hum certo genero de aruores ha tambem pelo mato détro na capitania de Paranambuco a que chamam Co pahíbas de q́ le tira balfamo muy falueifero \& proueirofo em extremo pera infirmida des de muitas maneiras, principalmente nas que procederm de frialdadecaufa grandes effectos \& cira codas as dores por graurs ą fejam em muiro breuc elpaço. Pera feridas ou quars y̆e oucras chagas, trm a mesma vireude as quaes tanto que com elle the acodem, Laram muy de pre $\int_{2}, 2$ cirz os $\int_{8}$ -

D268

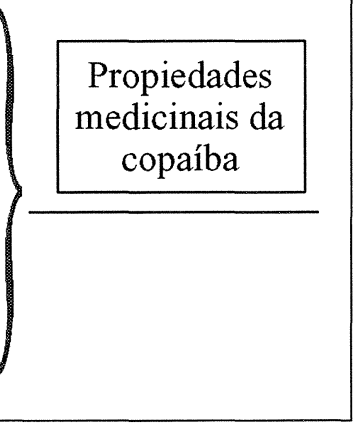

Jean de Lery, em sua Viagem à terra do Brasil (1578), procura contar apenas o que "vê, ouve e observa". Anexo à obra encontra-se o Colóquio, onde podemos encontrar um dicionário tupi-português. Sua nomenclatura compõe-se, em parte, de frases em forma dialogal, típicas dos dicionários bilíngües de viajantes. Outros verbetes, porém, têm como programa de informações a entrada em tupi, seu equivalente em português e uma definição entre parênteses, como podemos observar no exemplo abaixo:

Tapirusú: Tapir grande. (Animal semi-asno, semivaca, assim chamado por eles) (Lery 1980: 278). 
Fernão Cardim, em seu livro Tratado da Terra e da Gente do Brasil (1583), procede à descrição de muitas coisas sob uma forma dicionarística, embora em texto corrido:

Uçá-uçá é um gênero de caraıguejos que se achão na lama, e são infinitos, é o sustentamento de toda esta terra, maxime dos escravos da Guiné, e índios da terra (Cardim 1980: 51).

Falamos aqui de forma dicionarística na medida em que as informações acima se dispõem na seqüência entrada $(U c ̧ a ́$-uçá) + enunciado lexicográfico (definicional/enciclopédico), ambos ligados por uma cópula explícita (verbo ser: é).

Gabriel Soares de Souza, em seu Tratado Descritivo do Brasil, de 1587, também descreve certas espécies da fauna brasileira em forma semelhante a de um verbete:

Jaguapitanga é uma alimária do tamanho de um cachorro, de cor preta, e tem o rosto de cordeiro; tem pouca carne, as unhas agudas, e é tão ligeira que se mantém no mato de aves que andam pelo chão, toma a cosso, e em povoado faz ofício de raposa, despovoa uma fazenda de galinha que furta (Souza 1987: 247).

Nesse caso, a "microestrutura" apresenta um modelo semelhante ao do exemplo anterior, ou seja, uma entrada (jaguapitanga) + enunciado definicional, ligados pela cópula $e$.

As obras que levantamos acima não tratam especificamente de Medicina: descrevem a natureza e o modo de vida das populações locais. Outras, porém, dedicam-se a temas mais pontuais, ligados mais diretamente à Medicina, destacando-se dentre elas:

\begin{tabular}{|l|l|l|}
\hline 1613 & Pero de Castillo & $\begin{array}{l}\text { Nomes das partes do corpo humano, pella } \\
\text { lingua do Brasil, cõ primeiras, segundas \& } \\
\end{array}$ \\
& & terceiras pessoas \& mais differenças $q$ \\
& nelles ha; mujto necessarios \\
& aosconfessores que se occupão no \\
& menisterio de ounir confissôes, \& ajudar \\
& aos jndios onde decontino serue. Juntos por \\
& ordem alphabetica, pera mais facilmente se \\
& achare, \& sabere; pellopadre \\
\hline
\end{tabular}




\begin{tabular}{|l|l|l|}
\hline 1623 & Aleixo de Abreu & Tratado de las siete enfermedades (Lisboa) \\
\hline 1648 & $\begin{array}{l}\text { Romão Rosia Reinhipo } \\
\text { (pseud. Simão Pinheiro } \\
\text { Mourão) }\end{array}$ & $\begin{array}{l}\text { Tratado único das bexigas e sarampo } \\
\text { (Lisboa) }\end{array}$ \\
\hline 1648 & $\begin{array}{l}\text { Guilielmi Pisonis, } \\
\text { Georgi Marcgravi de } \\
\text { Liebstad, } \\
\text { Ioannes de Laet }\end{array}$ & $\begin{array}{l}\text { Historia naturalis Brasiliae. Lugdum } \\
\text { Botavorum : Lud. Elzevirium, [5], 122, [1], } \\
\text { 253, [7] p., [8] f. de lams. : il. ; 42cm [in } \\
\text { folio]. Pagina de rosto gravada, capitais e } \\
\text { vinhetas ornamentais }\end{array}$ \\
\hline 1694 & João Ferreira da Rosa & $\begin{array}{l}\text { Tratado único da constituição pestilencial } \\
\text { de Pernambuco }\end{array}$ \\
\hline 1716 & J. C. Semedo & Polyanthea Medicinale \\
\hline 1770 & Padre Francisco Lima & $\begin{array}{l}\text { Dioscorides brasilicus de medicinalibus } \\
\text { brasiliae plantae }\end{array}$ \\
\hline 1803 & Bernardino A. Gomes & $\begin{array}{l}\text { Observações Botanico-Medicas sobre } \\
\text { Algumas Plantas do Brasil (Lisboa) }\end{array}$ \\
\hline
\end{tabular}

Essas referências constituem-se, em sua maior parte, de compêndios que descrevem doenças. Neles a terminologia médica se apresenta sob a forma científica (em latim), em português, línguas indígenas e outras. Dentre essas obras encontra-se um dicionário médico. De fato, podemos considerar a obra de Pero de Castillo, de 1613, como o primeiro dicionário de Medicina brasileiro. Devido à importância desse trabalho, ater-nos-emos a ele mais adiante. Outra obra que merece destaque é a Historia Naturalis Brasiliae, que também analisaremos amiúde.

Se observarmos os locais de publicação das obras acima mencionadas, verificaremos que, até o início do século XIX, boa parte delas era editada em Portugal ou em outra cidade européia, uma vez que não era permitido publicar no Brasil Colônia. Essa situação só se modificou com a instalação da Família Real Portuguesa no Rio de Janeiro, em 1808.

Seguindo o mesmo raciocínio aplicado às obras anteriormente vistas neste trabalho, as que se encontram na lista abaixo também se caracterizam por estudos de natureza médico-botânica nos quais que a termi- 
nologia científica e popular designativa das enfermidades e plantas medicinais é descrita e definida. Muitas delas, porém, já foram publicadas no Brasil:

\begin{tabular}{|c|c|c|}
\hline 1836 & A. L. P. da Silva Manso & $\begin{array}{l}\text { Enumeração das substâncias brasileiras } \\
\text { que podem produzir a catarse (Rio de } \\
\text { Janeiro) }\end{array}$ \\
\hline 1844 & $\begin{array}{l}\text { Martius } \\
\text { K. F. Ph. Von Martius }\end{array}$ & $\begin{array}{l}\text { Systema Materiae Medicae Vegetabilis } \\
\text { Brasiliensis, Index Nominum Plantarum. } \\
\text { Natureza, doenças, Medicina e Remédios } \\
\text { dos indios Brasileiros }\end{array}$ \\
\hline 1854 & $\begin{array}{l}\text { Henrique Veloso } \\
\text { d'Oliveira }\end{array}$ & $\begin{array}{l}\text { Systema de Materia Medica vegetal } \\
\text { brasileira contendo o catálogo e } \\
\text { classificação de todas as plantas } \\
\text { brasileiras conhecidas - obra utilíssima e } \\
\text { ilustrativa extraída e traduzida das obras de } \\
\text { C. Phil. Martius, Indice alfabético das } \\
\text { plantas (Rio de Janeiro) }\end{array}$ \\
\hline 1871 & $\begin{array}{l}\text { Joaquim Monteiro } \\
\text { Caminhoá }\end{array}$ & $\begin{array}{l}\text { Das plantas tóxicas do Brasil (Rio de } \\
\text { Janeiro) }\end{array}$ \\
\hline 1877 & J. M. Caminhoá & $\begin{array}{l}\text { Elementos de Botânica Geral e Médica } \\
\text { (Rio de Janeiro) }\end{array}$ \\
\hline 1881 & Mello Moraes & $\begin{array}{l}\text { Phytogeographia ou Botânica Brasileira } \\
\text { Aplicada à Medicina, às Artes e à Indústria } \\
\text { (Rio de Janeiro) }\end{array}$ \\
\hline 1888 & $\begin{array}{l}\text { Theodoro Peckolt e } \\
\text { G. Peckolt }\end{array}$ & $\begin{array}{l}\text { História das Plantas Medicinais e Uteis do } \\
\text { Brasil. }\end{array}$ \\
\hline
\end{tabular}

Assim, percebemos que no século XIX a descrição da flora brasileira com propriedades medicinais atraía de modo particular cientistas brasileiros e estrangeiros. Aliás, esse tema é, até hoje, de interesse de inúmeras pesquisas. Muitas dessas obras dispõem dados sobre termos médicos sob a forma de enunciados definicionais, apresentando, portanto, um discurso lexicográfico em seu interior.

Entre os naturalistas que efetuaram pesquisas sobre a fauna, a flora e os povos do Brasil existia uma preocupação com a língua. $\mathrm{O}$ fato de 
seu objeto de estudo constituir-se de elementos ou questões ligadas a uma realidade desconhecida ou pouco conhecida do público-alvo de sua obra obrigava-os a tratarem, de um ponto de vista lingüístico, as unidades terminológicas que designam esses elementos. Nesse sentido, os autores lançam mão de um discurso lexicográfico ou de constituição do léxico especializado.

\subsection{A Historia NATURALIS BRASILIAE}

Guilherme Piso (1611-1678) e Georg Marcgrav (1610-1644) são os autores principais da obra magistral Historia Naturalis Brasiliae, publicada em 1648 na Holanda. Essa compõe-se de quatro livros dedicados a questões médicas -De Medicina Brasiliensi-de autoria de Piso (I. Dos ares, das águas e dos lugares (do Brasil); II. Das doenças endêmicas; III. Dos venenos e antídotos e IV. Das faculdades dos símplices) e de oito livros de Marcgrav: três dedicados ao estudo das plantas, um aos peixes, um às aves, um aos quadrúpedes e serpentes, e um à região e seus habitantes. As notas dispersas desses autores foram organizadas e receberam dados suplementares de João Laet (1593-1645).

Piso era membro da missão científica enviada pela Holanda ao Brasil no período em que vasta região, que vai de Pernambuco ao Rio Grande do Norte, ficou sob o domínio holandês (entre 1630 e 1654). Procedeu a um estudo científico aprofundado sobre doenças, remédios, propriedades medicinais de plantas, venenos e antídotos, características do ar e das águas do Brasil do século XVII, só tendo sido superado muitos anos mais tarde e, em alguns aspectos, nunca superado. Sua obra é considerada como fundadora da Medicina Tropical no Brasil e no mundo. Ao longo dos capítulos, freqüentemente o autor fornece informações de caráter lingüístico ou metalingüístico, notadamente no que concerne às diferentes designações em uma mesma língua (sinônimos ou parassinônimos) de uma espécie da flora, da fauna ou de doenças. Exemplos:

Segue-se agora a árvore silvestre Embira ou Pindaiba, como lhe chamam os índios (Piso 1948: 80).

Alguns portugueses lhe deram o nome de Pao velho e Pao mole por ter o córtice muito mole e rugoso (Piso 1948: 90). 
Em diversos momentos o autor aponta equivalentes em diferentes línguas, notadamente em indígena, português e holandês, mas também em espanhol e congolês, como podemos observar nos exemplos abaixo:

Além dessa, a Tatajba ou Pau amarelo, a Arariba, de casca vermelha, o Jacaranda, a Antuniba ou cedro branco, e muitas outras, óptimas para a feitura e construção de embarcações impermeáveis à água e de longa duração (Piso 1948: 6).

O chamado Cunapu, Nero pelos portugueses e Jacob Evertsz pelos holandeses, se encontra tanto no mar como nos rios (Piso 1948: 12).

O Inhame de S. Tomé, denominado pelos índios Cará e pelos congolenses Quiquoaquecongo, é planta de caule quadrado e um pouco torto de espaço a espaço (Piso 1948: 104).

Em diversas situações, a indicação de sinônimos ou de equivalentes se faz acompanhar de informações sobre a etimologia ou, mais propriamente, sobre a motivação da designação:

Entre as doenças crônicas é comum no Brasil a que ataca os nervos e produz profundo torpor dos membros. Os portugueses lhe chamam Air (sic) por nascer da inclemência do ar, de uma incompleta obstrução e da intempérie fria das partes nervosas (Piso 1948: 23).

Em primeiro lugar, a serpente Boicinininga, chamada pelos espanhóis Cascavel e Tangedor, por emitir da cauda um sonido como de guizo; vê-se tanto pelas estradas como pelos lugares desertos; move-se em tão célere reptação, que mais parece voar (Piso 1948: 47).

A disposição dos dados nos capítulos assemelha-se, não raro, a verbetes de enciclopédias, como se vê na figura que segue: 


\section{CAPítulo $\mathrm{XX11}$ \\ DOS MALES EXTERNOS CAUSADOS POR ALGUNS INSECTOS}

\section{BICHO DOS PES}

Esta terra cria uns minutíssimos vermículos chamados bicho pelos portugueses e t:onga pelos indigenas. Muitas vezes com prurids e raro con dor, criam-se nas extremiciades dos dedos dos pés. Atacam sobretudo e de preferència os que andam descalcos e perambulam por lugares arenosos, onde, por serem mui ouentes, gostam de viver invisíveis; evitam os pavimentos de pedras. A princípio ficam latentes durante algum tempo no exterior di pele. Logo, causando grande prurido, sobretudio nas plantas dos pés, penetram sern dano e nela se acoutam. Nada téem de comum

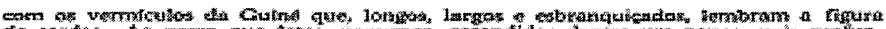

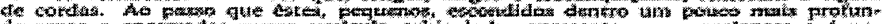

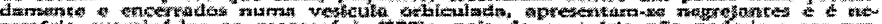

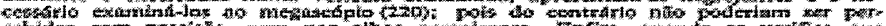

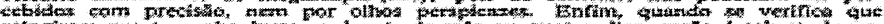

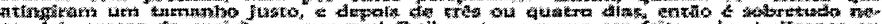

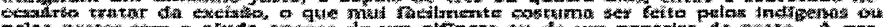

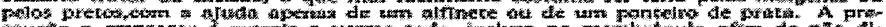

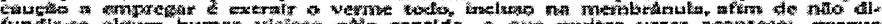

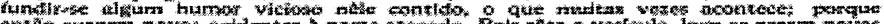

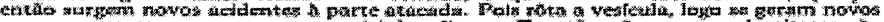

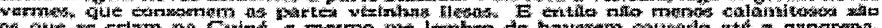

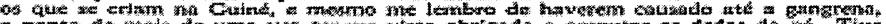

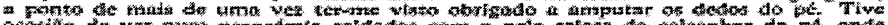

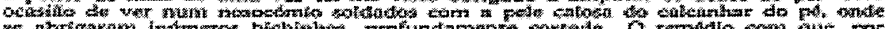

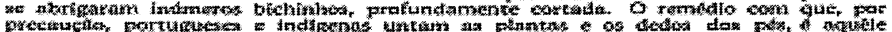

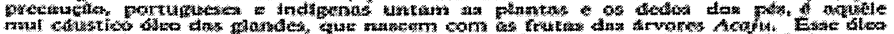

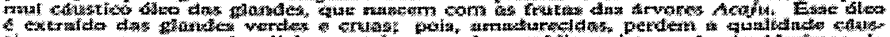

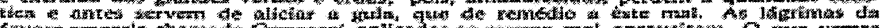

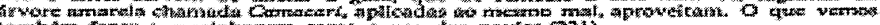

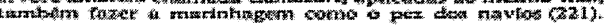

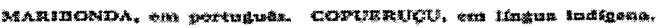

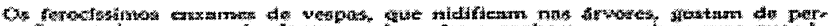

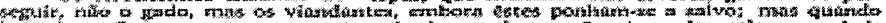

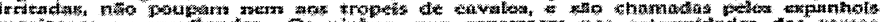

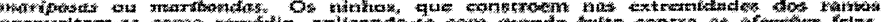

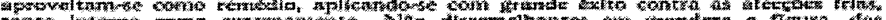

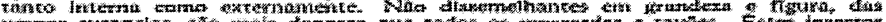

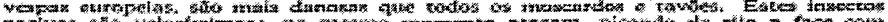

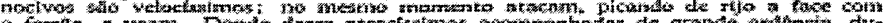

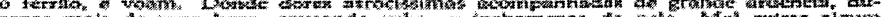

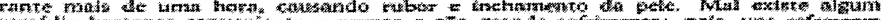

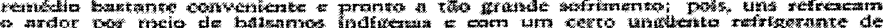

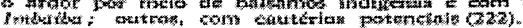

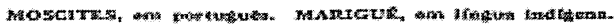

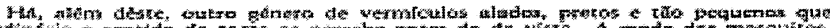

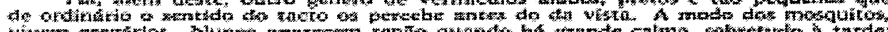

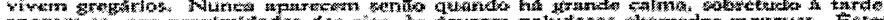

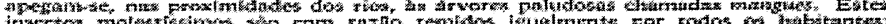

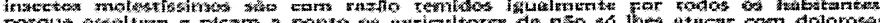

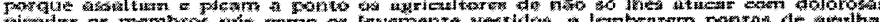

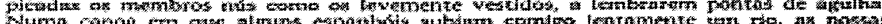

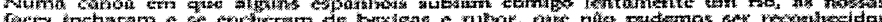

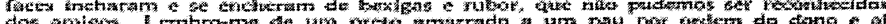

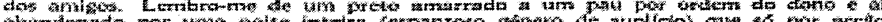

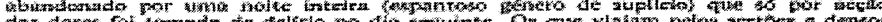

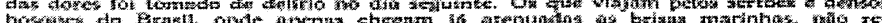

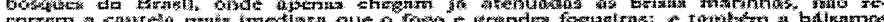

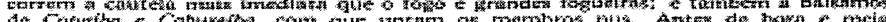

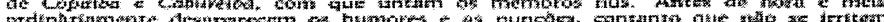

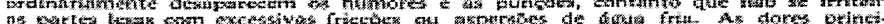

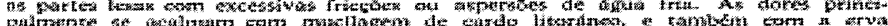

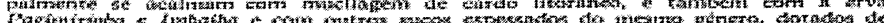

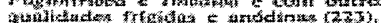

A ilustração acima permite constatar a semelhança entre a distribuição dos dados no Cap. XXII do Livro II e verbetes de dicionários enciclopédicos. Se identificarmos o texto acima com verbetes, podemos dizer que o programa de informações dos mesmos é o que segue: 
Entrada: termo em português, em maiúsculas e em negrito: microparadigma constante; Equivalente: termo em língua indígena, em maiúsculas e em negrito: microparadigma não-constante (em bicho do pé, somente o termo em português é dado); Enunciado lexicográfico (enciclopédico): microparadigma constante.

A separação entre os "verbetes" se faz por espaços em branco. Essa disposição no interior de um campo temático (Dos males externos causados por alguns insectos) segue, inclusive, a ordem alfabética das entradas em português: bicho dos pés, marimbonda, mostices. Outro exemplo de semelhança com um dicionário é o encontrado no Livro III:

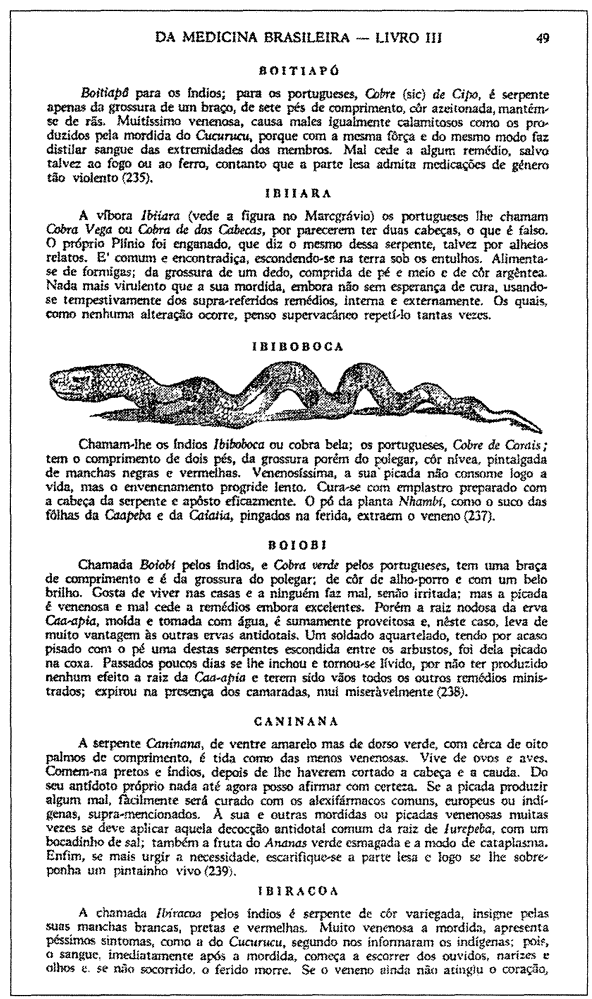
50
os mordidas saram com a carne da propria serpente cozida com raix de lurepeba, laborandi, Malsa isco, Caapeba, Catrypuba, acrescentando-se ramos de Nhambi com vinho, e fazendo aplicasōes internas. Ajunte-se um remédio externo, preparado com

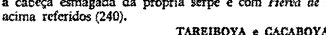

Enfim veem-se duas cobras que vivem ao modo dos anfiblos, ora nas lagoas, ora em terra; por isso podem com razăo se chamar hidras ou cobras de água, embora

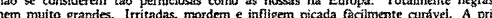

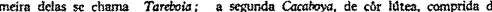
seis palmos, mais para temer dos agricultores, por thes devorar as galinhas, do que for instilar no homem veneno letal. Contudo, para maior segurarica, se algum veneno tiver, embotam-lhe a virtude as ervas Nhambi e a Erad de Cobras, apostas com arte (241) CROCODILO

Os crocodilos vivem nos esconderijos dos tios e das lagars, semeihantes aos africanos, mas muito menores; raro excedem cinco pés de comprimento. Chamamilhes lacaré os indios e os nossos, Caymans. Atacam os nadadores com a goela escancarada, causando-lhes granda foridas com ro medics vilgares, sobretudo porkm con a gordura do proprio anirnal. Tanto mordidos preso, por cheirarem fortemente a mirotécio. Tambèm as tripass deste lacaré, séces e reduzides a po, as aplicamn os incolas contra as doencas do callculo. Os ovos, que pơtem frequentemente acima de vinte ou trinta, excedem em tamanho os dos gansos, e sajo procurados e comidos nào so dos bárbaros, mas tamberm dos nossas soldados.
O mesmo entendo dizer da came extirpada do crocodila (242).

$$
\text { BIBORA }
$$

Dentre a tăo grande multidåo de lagartos encontradiços a cada passo nas selvas

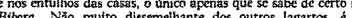
aperas excedente, corno dedo maior. De pele cimpenta o antes tirante a branco. corpo e todos os menbros sî́o mais grossos e prentes de veneno; a cauda enfirm muito mais breve e larga. A chaga por ela causada efunde uma sśnie dilúda e fétida, acompanhada de um tumor lfvicio, cardialgia, cólicas e grandes dores. Ainda näo se se descobriu um antidoto proprio a este mal. Por ande, bses padecim Ainde e sutros ESCOLOPENDRA. AMBUA. ESCORPIT̃O.

As escolopendras grandes e pequenas, bem corno os centipedes hirsutos chamados dos na classe dos animais venenosos, Aqueln metem-se pelas casas, èstes vivem nas selvas, e atacam não só as hortalicas como também homem. Os escorpitzes tâo semelhantes aos europents, embora näo tắo nocivos, e por iss as suas picadas de cura menos diffeil. Porcen conso a natureza destes trés insectos quentemente pelos autores, antes de mim, nem me ocorre nada para maior ilestraçăo, aqui me detenho. Porque so o bleo, que absorver as qualidades destes animais, se thes aplica conn bom exito as mordidas ou picadas (244)

$$
\text { NHANDUAGUACE }
$$

Aqui se acha, do gènero das aranhas, uma, monstruosa e de estupenda grandeza (talvez a mesma que Plinio refere ser encontrada nas Indias, to tamanho de um pardal. Nidifica nos cntulhos c nas concavidades das árvores veltas. e é cira mada Nhanduguacu. Ainda nâo se verificou se tece, ao modo das outras menores.
Muda de peé; negra e hirsuta, armada de dentes acuminados e mai longos, apteciada

Como podemos observar nas páginas acima, os dados são organizados em blocos separados entre si por espaços em branco, em forma de verbetes, que se seguem na vertical (organização típica da macroestru- 
tura dos dicionários). Na horizontal, o programa de informações da "microestrutura" respeita a seguinte seqüência:

Entrada: em maiúsculas, em negrito, centralizada, acima do texto: microparadigma constante;

Enunciado lexicográfico: microparadigma constante. Compõe-se das seguintes zonas: Entrada (em forma discursiva): termo em língua indígena: microparadigma não-constante; Equivalente (em forma discursiva): termo em português: microparadigma não-constante; Enunciado definicional e/ou enciclopédico: microparadigma constante; Ilustrações: microparadigma não-constante.

O discurso lexicográfico está, portanto, presente na obra de Piso, assim como o de constituição do léxico especializado, como se observa em sua preocupação de apresentar sinônimos, equivalentes e etimologia de termos que designam doenças, espécies da flora e fauna.

\subsection{A VIAGEM FILOSÓFICA}

A flora e a fauna brasileiras, inclusive de uso medicinal, foram descritas na Viagem Filosófica pelas Capitanias do Grão Pará, Rio Negro, Mato Grosso e Cuiabá, efetuada entre 1783 e 1792, por Alexandre Rodrigues Ferreira. Esse brasileiro, nascido na Bahia em abril de 1756, empreendeu, por solicitação de Dona Maria I, a famosa viagem ao Brasil, cujo objetivo era recolher material e fazer observações naturalistas, filosóficas e políticas sobre tudo o que encontrasse na terra. Ferreira teve o desgosto de vivenciar a usurpação de seu trabalho pelo naturalista francês Geoffoy de Saint-Hilaire e de não ver sua obra publicada.

A análise de Viagem permite-nos observar o recurso freqüente a um discurso lexicográfico, uma vez que os dados são organizados em capítulos temáticos e, no interior desses, dispostos sob a forma de verdadeiros verbetes, como podemos constatar na figura abaixo: 
VII. RELAÇÃO DOS ANIMAIS QUADRUAPEDES, SIL. VESTRES, QUE HABITAM NAS MATAS DE TODO O CONTINENTE DO ESTADO DO GRAO.PARA, DIVIDIDOS EM TRES PARTES: PRIMEIRA, DOS QUE SE APRESENTAM NAS MESAS POR MELHORES; SEGUNDA, DOS QUE COMEM OS INDIOS EM GERAL E ALGUINS BRANCOS QUANDO ANDAM EM DILIGENCIA PELO SERTAO; TERCEIRA, DOS QUE NAO SE COMEM

\section{PRIMEIRA}

\section{OS MAIS UTILIZADOS NA ALIMENTAÇAO EM GERAL}

1. QLIEIXADA - porco bravo ou do mato, que nunca atinge o tamanho dos porcos domésticos. Sua carne é excelente, feita de qualquer forma seja: cozida, assada, frita ou afogada.

2. QUEIXADA-BRANCA - Idêntica à acima diferenciando-se por ser mais brava e por ter o queixo branco.

3. CAITETU - menor que os antecedentes.

Dos porcos do mato em geral os indios do Rio Branco fazem colares e brincos com seus dentes, e suas presas são utilizadas em trabalhos de braganças.

4. PACA - animal com pele toda pintada de branco e carne muito gostosa, feita de qualquer maneira.

5. VEADO-BRANCO - a carne do veado branco, tida como seda, é muito gostosa quando estão gordos.

As peles curtidas são excelentes para assentos de cadeira e os sertanejos as usam muito para vestimenta, calções ,etc., etc. A pele do veado mateiro substitui a falta de sola por ser mais grossa. Os seus habitats são diferentes, porque, embora supostamente habite as matas, cada espécie tem locais prediletos onde costuma pastar, uns nas campinas, outros nas lagoas, outros nas capoeiras, outros nas matas virgens.

Não há homogeneidade no que concerne ao tipo de informação veiculada pelos enunciados definicionais, porém alguns apresentam adequação ao domínio e, sobretudo, ao campo conceptual no qual se inserem. É o caso das definições dos termos que designam espécies da 
fauna utilizadas na alimentação. Essas iniciam-se com uma descrição das características físicas dos animais e concluem-se com a especificação de suas qualidades enquanto alimento, como em queixada, paca e outros. No último trecho da página 133 e até à metade da página 134, Ferreira lista os termos que designam pessoas que se tornaram monstruosas por meio de algum artifício, dando a eles definição. Na segunda metade da página 134 e seguintes, descreve termos que designam pessoas monstruosas por natureza:

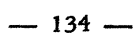

d - TURAZ e CARIPUNAS do rio Madeira.

Com um furo na cartilagem que divide interiormente as ventas. Relação do Rio da Madeira. Tit.

e - GAMELA

Com o lábio inferior rasgado circularmente e distendido por uma rodela de madeira, ficando orlada com o lábio em forma de gamela. Há muitas naçóes de gentios com os lábios e as orelhas furados.

$f$ - JURUPIXUNA Ou BOCA-PRETA

Com a face mascarada de cinza das folhas da palmeira $\mathbf{P u}_{\mathbf{u}}$ punheira. Memória de 20 de fevereiro de 1787.

$g$ - MAUA

Com o ventre espartilhado e cingido pelas entre-cascas das árvores. Memória de 20 de fevereiro de 1787.

$h$ - TUCURIA

As mulheres com o clitóris castrado.

\section{MONSTRUOSOS POR NATUREZA}

\section{i - CATAUXI OU PURUPURU}

Com as mãos e os pés malhados de branco. Memória de 4 de junho de 1788 .

I - Será certo, que entre as muitas nações de gentios que habitam no Juruá, confluente do rio Solimões, existe a dos CAUANAZ, espécie de pigmeus de estatura tão curta, que não passam de cinco palmos?

II - Será certo, que a dos UGINAS, no mesmo rio, consta de tapuias cardatos? Veja-se a certidão abaixo:

«Frei José de Santa Thereza Ribeiro, da Ordem de Nossa Senhora do Monte do Carmo, da antiga observância, etc. Certifico e juro inverbo sacendotis aos santos Evangelhos que, sendo eu missionário na antiga Aldeia de Paravari, a qual depois se mudou para o lugar que hoje se chama Nogueira, chegou a dita Aldeia, no ano de 1751 ou 1752, um homem chamado Manuel da Silva, natural de Pernambuco ou da Bahia, vindo do Japurá com alguns 
Aqui o autor apresenta um verdadeiro dicionário de termos que designam pessoas que, por natureza ou por qualquer artifício, tornaram-se monstruosas. O modelo de enunciado definicional não é homogêneo, indo da definição propriamente dita (como, por exemplo, em "Tucuria: as mulheres com o clitóris castrado") a um enunciado que ultrapassa o enciclopédico, assemelhando-se ao de dicionários críticos ou analíticos, como nos itens I e II do verbete dos termos catauxi ou purupuru. Esses dados referem-se a pessoas fisicamente monstruosas, o que é o objeto privilegiado de estudo de uma das áreas médicas, a Teratologia.

O recurso ao discurso lexicográfico é, portanto, freqüente na obra de Ferreira e de Piso, assim como de outros naturalistas; já em estudos médicos feitos por Von Martius, naturalista do século XIX, observa-se mais um discurso de constituição do léxico especializado, como veremos a seguir.

\subsection{A NATUREZA, DOENÇAS, MEDICINA E REMÉDIOS DOS ÍNDIOS BRASILEIROS (1844), DE KARL VON MARTIUS}

A Natureza, doenças, medicina e remédios dos índios brasileiros, obra de Karl F. Ph. Von Martius, foi publicada originalmente em 1844 em Munique (Alemanha). Esse documento é um dos mais completos no que concerne à saúde dos índios brasileiros do século XIX. As questões tratadas vêm sempre acompanhadas de dados sobre as designações indígenas, portuguesas e científicas, como podemos observar nos exemplos abaixo:

1. Febre: No que propriamente se refere á febre, já dissemos que a natureza apathica e indolente do índio e a pouca energia das funções nervosas não correspondem ao desenvolvimento das formas mórbidas, supportadas ou reflectidas pelo systema nervoso. Como caracter mais geral póde, neste particular, ser citado que o selvicola brasileiro não apresenta periodicidade muito decisiva em todas as suas doenças. Por isso, as febres intermittentes - taçúba em tupi, são mais raras do que as remittentes - taçúba-ayaba. A febre terçã - taçúba-ryry, é ainda, mais rara do que a quartã (Von Martius 1939: 103).

2. Varíola: De acordo com todas as informações fidedignas, a varíola era completamente desconhecida pelos índios, antes do povoamento português. Agora, porém, com a mais tremenda rapidez e deshuma- 
nas conseqüências, se alastra até aos mais remotos ermos, e cada tribu conhece e teme essa doença, como se fôra o mais pernicioso veneno para seu sangue. Na língua tupi é chamada-Mereba-ayaba $=$ doença maligna (Von Martius 1939: 97).

3. Espinhela: Outra doença chronica da digestão que por vezes observamos, nos índios, principalmente nos civilizados, descendentes dos tupis, nas Províncias da Bahia, Pernambuco e Maranhão, foi a reentrância do appendice xiphoide. Piso já havia mencionado esse mal como doença endêmica, - espinhela, assim chamada pelos portugueses, e por elle-prolapsus cartilaginis mucronatae (Von Martius 1939: 113).

4. Os conhecimentos anatomicos dos indios brasileiros se reduzem a estas occupações grosseiras. Conhecem os grandes órgãos no interior das cavidades e lhes dão nomes especiaes, muitas vezes bem significativos. Por exemplo, em tupi, os pulmões são chamados pya bubúi (figado fluctuante); o estomago cigiê-assú (grande estomago); 0 intestino cigiê-mirim (pequeno estômago) (Von Martius 1939: 216).

Ao longo da obra, as observações de caráter lingüístico e metalingüístico passam a ser mais freqüentes e mais profundas: além da indicação de equivalentes em duas ou mais línguas, o autor procede a análises da etimologia e do processo de formação das palavras, como poderemos observar na ilustrações que seguem:

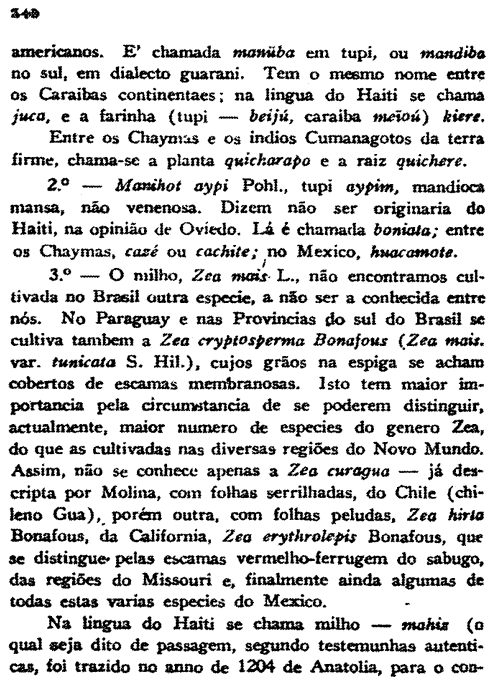

americanos. E' chamada marüba em tupi, ou mandiba no sul, em dialecto guarani. Tem o mesmo nome entre os Caraibas continentaes: na lingua do Haiti se chama juca, e a farinha (tupi - beijú, caraiba neïoú) kiere. Entre os Chayniss e os indios Cumanagotos da terra firme, chama-se a planta quicharapo e a raiz quichere.

2. - Manihot aypi Pohl., tupi aypim, mandioca mansa, năo venenosa. Dizem não ser originaria do Haiti, na opinião de Oviedo. Lá é chamarla boniala; entre os Chaymas, cazé ou cachite; no Mexico, hracamote.

$3^{\circ}$ - O nilho, Zea moxis L., não encontramos cultivada no Bresil cutra especie, a náo ser a contrecida entre nós. No Paraguay e nas Provincias do sul do Brasil se cultiva tambem a Zea cryptosperma Bonafous (Zea mais. var. tunicata S. Hil.), cujos grãos na espiga se acham cobertos de escamas membranosas. Isto tem maior importancia pela circumwtancia de se poderem distinguir, actualmente, maior numero de especies do genero Zea, do que as cultivadas nas diversas regiōes do Novo Mundo. Assim, näo se conhece apenas a Zea curagua - já descripta por Molina, com fothas serrilhadas, do Chile (chileno Gua), porén outra, com folhas peludas, Zea hirla Bonafous, da California, Zea erythrolepis Bonafous, que se distingue pelas escamas vermelho-ferrugem do sabugo, das regiōes do Missouri e, finalmente ainda algumas de todas estas varias especies do Mexico.

$\mathrm{Na}$ lingus do Haiti se chama milho - mahis (o qual seja dito de passagem, segundo testemunhas autenticas, toi trazido no anno de 1204 de Anatolia, para o con-

dado de Montferrat). Entre os Caraibas das Antilhas chama-se auachi, goari, nuarixi e nos do continente aousassi. Os Chaymas conhecem por: annaze, ayase ou yurar, os Aztecas por tlaolli; os Tupis por auaty - ou uba-tim, o que quer dizer: gramen rostratum (101). 4. - Varias especies de batatas, Convolvulus batatas L. e affins; Tupi : jetica (Heitich), Haiti : batola; Caraiba: napi; Azteca: comotli.

5. - Cará em tupi, igname no litoral de Paria, no Haiti ajê; sâo especies de Dioscoreas sarmentosas que produzem tuberculus comestiveis, por exemplo: $D$. alata, e outras. Mencionamos näo ser conhecido pelos aborigenes brasileiros outro tuberculo, chamado, não sabemos porque, tupincembit o Helianthus twberosus L.

Corrèa jả observou (Humb. Mouv. Esp. II. p. 409), que a planta não vegeta em estado silvestre no Brasil. Sua patria deve provavelmente ser procurada em Buenos Ayres, se não se demonstrar ser o Mexico.

6. - Taid - tayóba, mangaras, são nomes tupis das aracéas mansas mucilaginosas e feculentas, que são utilizadas como legumes, quando cozidas. - (Colocasia antiguarum e esculenta, Caladium poecile, sagittifolium, etc.). No Brasil, essas plantas são conhecidas por inhome. 7. - Murdubi, mandubi dos tupis, mani no Haiti. Arachis hypogaea, é comido crú e torrado. Fornece oleo apreciado.

(101) Mitho zaburro - abatiantan. Dicc. Bras. Port. E' possivel que ubd-iim exia erro typographipo; o certo t abati milho. (Nota de Pirajo da Silva). 







6. há verbetes que praticamente não contêm definição, apenas uma opinião pessoal do autor sobre alguma questão que o incomoda. Exemplo:

Vento máo. Um erro popular faz com que algumas pessoas dêem este nome à apoplexia, como se esta moléstia fosse produzida pelo vento (Chernoviz 1890: 199).

No que concerne aos aspectos lingüísticos mais propriamente ditos e ao seu tratamento lexicográfico, observa-se que:

- termos homônimos constituem entradas de verbetes diferentes. Exemplo: galo (moléstia) e galo (ave);

- a variação terminológica (lexical) vem expressa na própria entrada por uma seqüência de termos ligados pela conjunção ou, por uma remissão ou pela indicação do termo científico correspondente ao termo popular que constitui a entrada.

- a etimologia também é freqüentemente dada.

O objetivo maior da obra de Chernoviz era o de "auxiliar as famílias no conhecimento e nas formas de tratamento das moléstias, não se tratando, portanto, de um dicionário para especialistas" (Krieger 1998: 297). Essa característica também se encontra presente em outros dicionários médicos da época. De fato, "um dos principais princípios que regem a produção lexicográfica médica do século XIX no Brasil é de natureza pragmática. Vale dizer, a estrutura interna da obra preocupa-se em adequar-se, sob vários aspectos, às imagens de competência e, sobremaneira, de projeções do interesse informativo dos consulentes visados" (Krieger 1998: 302).

Do ponto de vista de sua tipologia, as obras lexicográficas especializadas em Medicina do século XIX, embora se denominassem Vocabulário, Dicionário ou Glossário, tinham mais propriamente um caráter enciclopédico. Essa característica dos dicionários de Medicina era uma marca da produção lexicográfica geral da época. 


\section{CONCLUSÃO}

Os aspectos aqui levantados são, a nosso ver, importantes para a compreensão do processo de construção do saber terminológico e terminográfico médico no Brasil. Se nos ativéssemos ao conceito de Terminografia tal como essa disciplina científica é concebida hoje, nossa pesquisa deveria se restringir aos dicionários especializados cuja elaboração se baseia em princípios teóricos e metodológicos próprios da Terminologia moderna. O número seria, então, muito reduzido e se limitaria às obras elaboradas nas Universidades em que se desenvolveram estudos em Terminologia (fundamentalmente a partir da década de 1980).

De acordo com a perspectiva que adotamos neste trabalho foi considerado um discurso lexicográfico existente em documentos que não se caracterizam como obras lexicográficas e os dicionários médicos propriamente ditos. Partimos, assim, do pressuposto de que o resgate da história da Terminografia brasileira não deve deixar de levar em consideração tanto dicionários, quanto outros documentos que trazem em seu bojo elementos precursores da Lexicografia especializada ou da Terminografia, neles se observando um discurso lexicográfico ou terminográfico, além de um discurso de constituição do léxico de áreas de especialidade.

Dentre esses documentos situam-se as cartas, os relatos de viajantes, narrativas oficiais, estudos científicos produzidos nos primórdios do período colonial que descreviam o Brasil em seus diferentes aspectos para fins diversos e que contribuíram em muito para a elucidação de léxicos indígenas e para o enriquecimento do universo lexical do português, sobretudo no que concerne a termos que designavam coisas exóticas ou doenças, próprias do local ou nele existentes, desconhecidas dos colonizadores. Ao descrever as coisas, descrevia-se também a terminologia científica e popular que as designava. Um destaque deve ser dado às obras dos naturalistas nas quais é evidente uma preocupação com o léxico e a presença de um discurso lexicográfico mono-, bi-, multilíngüe e/ou enciclopédico, ora em forma de texto corrido, ora no estilo de verbetes de dicionários.

No que concerne aos dicionários médicos produzidos no Brasil até o final do século XIX, ganha relevo o vocabulário bilíngüe de Pero de 
Castillo. Essa obra, de 1613, que listava os nomes das partes do corpo humano em tupi e em português, deu uma contribuição ao resgate da história da Anatomia e da Medicina no Brasil, podendo ser considerado como o primeiro dicionário de área médica de nosso país e como a primeira Nomina Anatômica nacional. Com efeito, somente a partir da segunda metade do século XIX é que a produção desse tipo de obra ganhou impulso devido à permissão para publicação em território nacional e aos avanços da Medicina ocorridos no Brasil e no mundo da época. Uma das principais características dos dicionários médicos do século XIX era seu cunho enciclopédico e o pouco rigor no trato dos dados lingüísticos. As entradas dos verbetes eram vistas mais como temas do que como termos.

\section{REFERÊNCIAS BIBLIOGRÁFICAS}

Ayrosa, Plinio (1937): Os Nomes das partes do corpo humano pella lingua do Brasil, de Pero de Castilho. Texto tupi-português e português-tupi do seculo XVII, São Paulo, Empresa Gráfica da Revista dos Tribunais.

CARDIM, Fernão (1980): Tratado da terra e gente do Brasil (1583), Belo Horizonte-São Paulo, Itatiaia-EDUSP.

CAstillo, Pero de (1937): Nomes das partes do corpo humano, pella lingua do Brasil, cõ primeiras, segundas \& terceiras pessoas \& mais differenças q nelles ha; mujto necessarios aos confessores que se occupão no menisterio de ouuir confissões, \& ajudar aos jndios onde de contino seru?. Juntos por ordem alphabetica, pera mais facilmente se achar?, \& saber?; pello padre PERO de CASTILHO da Companhia de Iesu. Anno 1613, São Paulo, Empresa Gráfica da Revista dos Tribunais.

FERreIRA, Alexandre Rodrigues (1972): Viagem filosófica pelas capitanias do Gão Pará, Rio Negro, Mato Grosso e Cuibá. Memórias (Zoologia e Botânica), Rio de Janeiro, Conselho Federal de Cultura.

Gandavo, Pero de Magalhães (1984): História da Província de Santa Cruz a que vulgarmente chamaos Brasil, ed. fac-similada, Lisboa, Biblioteca Nacional de Lisboa.

KrIeger, Maria da Graça (1998): “Terminografia médica no Brasil no século XIX", in J. Brumme (ed.), Actes del col-loqui: la història dels 
llenguatges iberoromànics d'especialitat (segles XVII-XIX): solucions per al present. 15-17 de maig de 1997, Barcelona, IULA, pp. 295-304.

LERY, Jean de (1980): Viagem à terra do Brasil, Belo Horizonte-São Paulo, Itatiaia-EDUSP.

Martius, K. F. Ph. Von (1939): Natureza, doenças, Medicina e Remédios dos índios Brasileiros (1844), São Paulo-Rio de Janeiro-Recife-Porto Alegre, Companhia Editora Nacional.

NunES, José Horta (1996): Discurso e instrumentos lingüísticos no Brasil: dos relatos de viajantes aos primeiros dicionários, Tese defendida na Universidade Estadual de Campinas-UNICAMP.

(2002): "Dicionarização no Brasil: condições e processo", in José Horta Nunes e Margarida Petter, História do saber lexical e constituição de um léxico brasileiro, São Paulo, Humanitas-Pontes, pp. 99-122.

ORgANISATION INTERNATIONALE DE NORMALISATION (1990): Terminologie - Vocabulaire. Genebra. ISO (Norme Internationale ISO 1087).

PIso, Guilherme (1948): De Medicina Brasiliensi, São Paulo, Imprensa Oficial do Estado de São Paulo, 4 vol.

— George MARCGRAV (1948): Historia naturalis Brasiliae, São Paulo, Imprensa Oficial do Estado de São Paulo.

SouzA, Gabriel Soares de (1987): Tratado descritivo do Brasil (1587), São Paulo, Companhia Editora Nacional.

VERDELHO, Telmo (2002): "Dicionários portugueses, breve história", in José Horta Nunes e Margarida Petter, História do saber lexical e constituição de um léxico brasileiro, São Paulo, Humanitas-Pontes, pp. 15-64. 